\title{
ONLINE RELEASE OF AN EDUCATIONAL BOOKLET ADDRESSING SCLERODERMIC HANDS CARE
}

Barbara Niquini Assunçãoํㅡ, Vivian Guerra de Faria², Thalles Guilherme de Almeida², Caio Carvalhais Chaves², João Victor de Pinho Costa², Luiza Castro Fernandes², Alessandra Rodrigues Hansen Ferreira², Anderson Ramos Lisboa², Felipe Souza da Silva², Liliane Amaral2 ${ }^{2}$ Maria Raquel Costa Pinto², Flávia Patrícia Sena Teixeira Santos², Leandro Augusto Tanure², Gilda Aparecida Ferreira², Júnia Amorim Andrade², Débora Cerqueira Calderaro ${ }^{2, *}$

1.Faculdade de Ciências Médicas de Minas Gerais, Belo Horizonte (MG), Brazil. 2.Universidade Federal de Minas Gerais, Belo Horizonte (MG), Brazil.

*Corresponding author: dccalderaro@gmail.com

\section{BACKGROUND}

Systemic sclerosis (SSc) is an autoimmune disease characterized by excessive collagen deposition in the skin and many organs, leading to fibrosis and reduced function. Clinical involvement of the hands involves edema, fibrosis, calcium deposits in the soft tissue (calcinosis), Raynaud's phenomenon and digital ulcers, leading to hands and joint pain and deformities, tenosynovitis, muscle weakness and, finally, limited movement and function loss. The premature practice of stretching and exercises can relieve these symptoms and help to maintain joint range and function of the hands. Thus, the preparation, distribution and dissemination of educational materials, such as booklets with guidance on hand care and instructions on stretching exercises play a relevant role in the treatment of SSC.

\section{METHODS}

In 2020, a university extension project aiming at patients educating developed an educational booklet with occupational therapy guidelines to provide information about SSc and measures to prevent complications and improve functionality. People with the disease were invited to review that booklet and provided suggestions for more subjects that should be addressed by new educational materials. Hands care was one of these subjects. In response to this demand, a literature search was carried out and a new booklet was prepared with guidelines on exercises and hand care in SSc, aiming to prevent the loss of functionality and weakening of the hands, as well as to improve the quality of life of these patients.

\section{RESULTS}

The booklet was prepared with accessible language and images easy to understand. Due to the social distance imposed by the COVID-19 pandemic and to increase its reach, it was spread online through the website of the medical school and on the social networks of the extension project participants. The booklet was published on the University's website on June 9, 2021 and, until July 5, 2021, it had reached 195 views. The dissemination of this material continues, in order to lead information to a significant number of people.

\section{CONCLUSION}

Educational materials are relevant tools in promoting knowledge about SSc and promoting self-care by patients. The development of educational materials is relevant, especially for rare and little-known health conditions, such as SSc. This material provides reliable information on how to deal with symptoms, mainly through the demonstration of techniques that help in hand care, and, in addition, it provides information about the importance of stretching and strengthening exercises, which help in prevention of hands functional loss.

\section{KEYWORDS}

Systemic sclerosis, Patient Education as topic, Hands, Care, Self.

Realização: 